\title{
Potential application of Hibiscus sabdariffa L. (Malvaceae) and Lawsonia inermis L. (Lythraceae) aqueous extracts for assessment of viability of protoscolices from hydatid cysts
}

ELSAYED ELSIDDIG ELOWNI ( $\nabla$ elsayedelowni@gmail.com )

University of Khartoum https://orcid.org/0000-0002-9104-5268

Ghada Hassan Abdelnabi

"University of Khartoum"

Mohamad Fadl AhmaD

University of Khartoum

Reem Mustafa Badawi

University of Khartoum

Research article

Keywords: Hibiscus sabdariffa, Lawsonia inermis, protoscolices, viability, camel, hydatid cyst

Posted Date: August 31st, 2019

DOl: https://doi.org/10.21203/rs.2.13698/v1

License: (c) (1) This work is licensed under a Creative Commons Attribution 4.0 International License.

Read Full License 


\section{Abstract}

Background A number of commercial stains have been used to assess the viability of protoscolices ( defined as the capacity of being alive ) that develop in hydatid cysts, the infective stage of the tapeworm Echinococcus granulosus (s.l). There has been a remarkable increase of interest in natural product research over the past few decades for application of these products in a diversity of fields. Hibiscus sabdariffa L. (Malvaceae) is a flowering plant widely cultivated in the Sudan. Aqueous extracts from plant calyces have characteristic brilliant red colouration due to the presence of anthocyanins, an important group of water-soluble plant pigments. Lawsonia inermis L. (Lythraceae), commonly called "Henna" or "Mehndi ", is famous for having dyeing properties due to the presence of lawsone, a red-orange pigment extracted from plant leaves. Objective was to assess the viability of protoscolices of camel origin following exposure to aqueous extracts of $\mathrm{H}$. sabdariffa calyces or L. inermis leaves taking advantage of the kinetically distinct molecular transfer systems of the Echinococcus protoscolex for uptake of materials across the tegument (external body covering). Results Viable protoscolices are capable of exclusion of plant pigment obtained from either $\mathrm{H}$. sabdariffa or $\mathrm{L}$. inermis whereas dead protoscolices uptake the pigment in both occasions. Performance is comparable to eosin.Conclusions It is suggested that extracts of both plants can be used effectively as a cheap and a readily available natural material for assessment of viability of protoscolices. Regarding the remarkable diversity of functions of the tapeworm tegument, it is proposed that the Echinococcus protoscolex can be employed as an experimental model in studies concerned with tapeworm natural protective responses in hostile environments, for instance upon exposure to antiparasitic drugs or host's body defences.

\section{Background}

Cystic echinococcosis (hydatidosis) is a serious helminthic zoonotic disease of economic and public health concern resulting from tissue invasion with hydatid cysts the infective metacestode (larval) stage of the tapeworm Echinococcus granulosus sensu lato (s.l.). The cysts develop in a broad spectrum of domestic and wild angulates belonging to different groups, including Bovidae, Cervidae, Equidae and Camelidaeas intermediate hosts and humans as an aberrant host [1]. The definitive hosts, mainly dogs, become infected with the adult tapeworm when they ingest with viscera fertile hydatid cysts containing protoscolices. Various commercial stains such as eosin, Giemsa stain, trypan blue and other stains [2,3] have been used in in vitro tests to assess the viability of protoscolices (defined as the capacity of being alive) in order to avoid various problems [4] associated with animal experimentation involving the canine (dog) definitive host. There has been a remarkable increase of interest in natural product research over the past few decades for application of these products in a diversity of fields such as medicine, agriculture, nutraceutical or cosmetics industries. Hibiscus sabdariffa L. (Malvaceae) (also known as roselle) is a flowering plant widely cultivated in the Sudan mainly for export of the calyx. It is locally known as "Karkadai". Aqueous extracts from calyces have characteristic brilliant red colouration due to the presence of anthocyanins [5, 6], an important group of water-soluble plant pigments commonly found in various fruits and vegetables [7]. This attractive natural colouration found wide application in the food 
industry as alternative to synthetic dyes. Lawsonia inermis L. (Lythraceae), commonly called "Henna" or "Mehndi ", is a widespread plant universally famous for having dyeing properties [8]. It is commonly used for personal adornment especially body art and in industry. The plant has also been described to have medicinal benefits $[9,10]$. Henna's characteristic staining properties stem from the compound 2-hydroxy1, 4-naphthoquinone, known as lawsone; a red-orange pigment extracted from plant leaves [11]. The present study examines the potential application of aqueous extracts of $H$. sabdariffa calyces and $L$. inermis leaves for assessment of viability of protoscolices from hydatid cysts taking uptake/exclusion of plant pigment as criteria.

\section{Methods}

\section{Protoscolices}

Hydatid cysts were obtained from the lungs of naturally infected camels slaughtered in a local market in Gezeira State, Central Sudan. Cysts were transported intact to the parasitology laboratory, Faculty of Veterinary Medicine, University of Khartoum. They were grossly examined for any evidence of pathological changes such as caseation or calcification. Those with a tender texture, apparently containing fluid, were washed thoroughly from debris, dissected free from host adventitia and slit open to recover cystic fluid. Protoscolices were recovered by centrifugation of cyst fluid at 2,000 rpm for $2 \mathrm{~min}$. The supernatant was discarded.

\section{Preparation of Extracts}

Crude, newly harvested $H$. sabdariffa sun-dried calyces of $35 \mathrm{~g}$ were obtained from a local Sudanese market in Khartoum known for selling $H$. sabdariffa (locally known as Karkadai) and other indigenous plants for domestic use. They were soaked in distilled water to give a $12.5 \% \mathrm{w} / \mathrm{v}$ mix. The preparation was kept in a refrigerator for 24 hours. By this time, water extraction is expected to be complete [12]. The preparation was subsequently strained through a fine mesh and strained fluid was centrifuged at 2,000 rpm for 3 minutes to obtain a clear working solution. L. inermis aqueous extract was prepared in a similar manner using a $10 \% \mathrm{w} / \mathrm{v}$ crude leaves mix. In both occasions, $\mathrm{pH}$ of the working solution was determined using pH meter (AD8000 Bench Meter, Adwa Instruments, Hungary).

\section{Treatment}

$2.0 \mathrm{ml}$ of either $H$. sabdariffa or L. inermis working solution was added to protoscolex sediments in test tubes. The contents were agitated with slight movements and incubated for $5 \mathrm{~min}$ at room temperature. Tubes were centrifuged at $1500 \mathrm{rpm}$ for 2 min and the supernatant was discarded leaving few drops with the pellet. Protoscolices were transferred with micropipettes to glass slides, covered with cover glass slip and examined under light microscopy. For comparative purposes, protoscolices were treated with eosin $0.1 \%$ aqueous solution, a method widely used for assessment of viability of protoscolices from hydatid cysts [13, 14, 15]. According to Miman et al. [2], use of the stain at a concentration of $0.1-1 \%$ is ideal for assessment of viability of protoscolices. To verify the criteria by which viability is assessed, control tests 
were performed with dead protoscolices using protoscolices previously exposed to hot water in water bath at $60^{\circ} \mathrm{C}$ for $5 \mathrm{~min}$. Results by Moazeni and Alipour-Chaharmahali[16] indicate that exposure of protoscolices to temperatures at 50,55 , or $60^{\circ} \mathrm{C}$ for 5,2 or $1 \mathrm{~min}$, respectively, is $100 \%$ lethal to protoscolices.

\section{Results}

The Figure 1 shows the gross morphology of normal (alive) Echinococcus protoscolices upon recovery from camel hydatid cysts.

Control tests indicated that normal protoscolices exposed to eosin did not take up the stain (Fig. 2) and they maintained an unchanged color. Protoscolices subjected to thermal death following exposure to hot water, however, were permeable to the stain and appeared red in color (Fig. 3).

Tests with $H$. sabdariffa calyx extract showed that normal protoscolices did not take up plant pigment (Fig. 4) whereas dead protoscolices acquired the pigment distinctive color (Fig. 5).

A similar result was obtained when $L$. inermis leaf extract was applied to normal or dead protoscolices (Figs. 6 and 7, respectively).

\section{Discussion}

Among parasitic helminths, tapeworms have an exceptionally highly dynamic and a metabolically active body cover (tegument) capable of performing digestive, absorptive and protective functions $[16,17,18]$ providing a surface for interaction with the environment in which the worms reside. According to Pappas [19], four distinct mechanisms, viz pinocytosis, diffusion, active transport and facilitated diffusion, are implicated in nutrient uptake by tapeworms. The Echinococcus protoscolex, in particular, has been shown to have kinetically distinct molecular transfer systems for uptake of materials across the tegument [20]. Such properties enable the viability of protoscolices to be assessed taking uptake/exclusion of exogenous material as criteria. Results show that viable protoscolices are capable of exclusion of plant pigment obtained from either $H$. sabdariffa calyces or $L$. inermis leaves whereas dead protoscolices uptake the pigment in both occasions. The actual mechanism, by which either function is performed at the tegument cell level, however, remains to be defined. Using the yeast Saccharomyces cerevisiae as model organism, Kwolek-Mirek and Zadrag-Teczain [21] introduced a classification of methods for assessment of viability of cells. These include stain-based methods whose mechanisms of action depend on the properties of the cell membrane. Methylene blue, a synthetic basic dye and a redox indicator (also called an oxidation-reduction indicator), for instance, has been classified as one of the dyes that traverse cell membrane into both living and dead cells. Living cells are able to reduce the dye and remain colorless whereas dead cells are unable to do so and are therefore stained blue. Similarly, a dye like phloxine B also penetrates into both living and dead yeast cells [22]. In this case, metabolically active cells pump out the dye and remain colorless, whereas dead cells passively incorporate the dye and 
are stained red. Although it is difficult to make comparisons between different organisms, tests with methylene blue [4] showed that viable and dead Echinococcus protoscolices uptake the dye as do living and dead yeast cells. Viable protoscolices are capable of reducing the oxidized dye and instantly lose the dye blue color whereas dead protoscolices fail to do so and they retain the color. According to Lumsden [23], tapeworms, with no trace of a mouth or digestive canal, with neither a respiratory nor a bloodvascular system [24], utilize the tegument alone for chemical interchange with the host; the tegument glycocalyx layer serving as a binding surface for inorganic ions and higher molecular weight organic compounds. Such properties of the tegument are translated into a remarkable diversity of functions including contact-digestion at the surface of the worm [23] and protection of the parasite against injurious elements such as hosts's digestive enzymes, bile acids or components of the hosts's immune reaction [17]. The present study indicates that viable Echinococcus protoscolices are potentially capable of exclusion of extraneous, possibly harmful material. They may, therefore, be employed as experimental model in studies concerned with tapeworm natural protective responses in hostile environments, for instance upon exposure to antiparasitic drugs or immunologically-mediated host's body defences.

Generally anthocyanin pigments, including Hibiscus anthocyanins [25], are potentially unstable; the pH being a major factor that influences pigment color variations and stability $[6,26]$. The present study indicates that an $\mathrm{H}$. sabdariffa calyx aqueous extract at $\mathrm{pH} 1.64$ and a $L$. inermis leaf extract at $\mathrm{pH} 3.13$ provide verifiable results. Further tests may be necessary to standardize a technique for protoscolex viability assay using the extract material.

\section{Conclusion}

It is concluded that aqueous extracts of either $H$. sabdariffa calyces or $L$. inermis leaves can be used effectively as a cheap and a readily available natural material for assessment of viability of protoscolices from hydatid cysts. Performance of the two plant extract materials is comparable to eosin.

\section{List Of Abbreviations}

Echinococcus granulosus (s.l): Echinococcus granulosus sensu lato; H. sabdariffa: Hibiscus sabdariffa; L. inermis: Lawsonia inermis; w/v: weight/ volume.

\section{Declarations}

Ethics approval and consent to participate: Not applicable

Consent for publication: Not applicable

Availability of data and materials: Not applicable

Competing interests: The authors declare that they have no competing interests. 
Funding: This work was supported by a grant from the Deanship of Scientific Research, University of Khartoum, specifically assigned for the purchase of photography equipment. Authors' contributions: EE designed the study, provided scientific background, performed practical work, wrote the draft of the paper, GHA provided and prepared study materials and participated in interpretation of results. Similarly MFA performed practical work and was a contributor in writing the manuscript. RMB attended to laboratory procedures and participated in practical work. All authors read and approved the final manuscript."

\section{Acknowledgements}

The authors wish to thank Dr. Mai D. Ahmed, Department of Botany and Agricultural Biotechnology, Faculty of Agriculture, for confirming the taxonomic identity of Hibiscus sabdariffa and Lawsonia inermis, Dr. Ibrahim Higazi, Rofaa Veterinary Administration, for securing hydatid cyst specimens and Mr. Awadalla Abedelmoniem for transport of specimens.

\section{Authors' information}

Department of Parasitology, Faculty of Veterinary Medicine, University of Khartoum, Sudan

\section{References}

1. WHO/OIE. Manual on Echinococcosis in Humans and Animals: a Public Health Problem of Global Concern.Eckert J, Gemmell MA, Meslin FX, Pawłowski ZS, Editors. World Organization for Animal Health and World Health Organization. 2002.

2. Miman O, Aycan OM, Aydin C, Atambay M. What should be the concentration of eosin to qualification of ideal staining for viability determination on hydatid cyst? Turk Hij Den Biyol Derg 2010; 67(1): 21-26.

3. Esfandiari B, Youssef MR. Comparison of eosin and trypan blue staining in viability of hydatid cyst protoscolices. Glob Vet. 2010; 4(5): 456-8.

4. Elowni EE, Ahmad MF, Abdelnabi GH, Badawi RM. Validation of the methylene blue test for assessment of viability of protoscolices from hydatid cysts. Open Vet. J. 2019; 9(2): 172-176.

Doi: http://dx.doi.org/10.4314/ovj.v9i2.13.

5. Abou-Arab AA, Abu-Salem, FM, Abou-Arab EA. Physico-chemical properties of natural pigments (anthocyanin) extracted from roselle calyces (Hibiscus sabdariffa).. J Am Sci. 2011; 7: 445- 456.

6. Shruthi VH, Ramachandra CT, Udaykumar N, Sharanagouda H, Nagaraj N, Kurubar RA. Roselle (Hibiscus sabdariffa L) as a source of natural color: A review. Plant Arch. 2016; 16 (2):515-522.

7. Horbowicz M, Kosson R, Grzesiuk A, Dbski H. Anthocyanins of fruits and vegetables - their occurrence, analysis and role in human nutrition. Veg Crop Res Bull. 2008; 68: 5-22. 
8. Babili FE, Valentin A, Chatelain C. Lawsonia inermis: its anatomy and its antimalarial, antioxidant and human breast cancer cells MCF7 activities. Pharmaceut Anal Acta. 2013; 4: 203. Doi: 10.4172/2153 2435.1000203.

9. Zumrutdal E, Ozaslan M. A miracle plant for the herbal pharmacy; Henna (Lawsonia inermis). Int J Pharmacol. 2012; 8:483-9.

10. Sharma RK, Goel A, Bhatia A K. Lawsonia inermis Linn: a plant with cosmetic and medical benefits. Int J Appl Sci. Biotechnol. 2016; 4(1), 15-20. Doi: 10.3126/ijasbt.v4i1. 14728.

11. Dominici L, Cerbone B, Villarini M, Pagiotti R, Moretti M. In vitro genotoxicity testing of Lawsonia inermis and henna extracts in HepG2 cells by the comet assay. Int J Nat Prod Sci. 2013; 3(2): 12-21.

12. Eltayeib AA, Hamade H. Phytochemical and chemical composition of water extract of Hibiscus sabdariffa (red karkade calyces) in North Kordofan State Sudan. Int J Adv Res Chem Sci. (IJARCS) 2014; 1(6): 10-13.

13. Yones DA, Taher GA, Ibraheim ZZ. In vitro effects of some herbs used in Egyptian traditional medicine on viability of protoscolices of hydatid cysts. Korean J Parasitol. 2011; 49(3): 255-263.

Doi: 10.3347/kjp.2011.49.3.255.

14. Mahmoudvand H, Dezaki ES, Kheirandish F, Ezatpour B , Jahanbakhsh S, Harandi MF. Scolicidal effects of black cumin seed (Nigella sativa) essential oil on hydatid cysts. Korean J Parasitol. 2014; 52(6): 653-659. Doi: 10.3347/kjp.2014.52.6.653.

15. Mokhtaria K, Ammar SSM. Frozen hydatid cysts can replace incineration and sterilize cysts. Open Vet J. 2019; 9(1):1- 4 .

15. Moazeni M, Alipour-Chaharmahali MR. Echinococcus granulosus: in vitro effectiveness of warm water on protoscolices. Exp Parasitol. 2011; 127(1): 14-17.

16. Lumsden RD, Specian R. The morphology, histology and fine structure of the adult stage of the Cyclophyllidean tapeworm Hymenolepis diminuta. In: Biology of the Tapeworm Hymenolepis diminuta. Arai HP editor. Academic Press; 1980. P. 157-280.

17. Podesta RB. 1980. Concepts of membrane biology in Hymenolepis diminuta. In: Biology of the Tapeworm Hymenolepis diminuta. Arai HP editor. Academic Press; 1980. P. 505-549.

18. Dalton JP, Skelly P, Halton DW. Role of the tegument and gut in nutrient uptake by parasitic platyhelminthes. Can J Zool. 2004; 82(2): 211-232.

19. Pappas PW. Nutrient uptake by tapeworms. In: Transport Processes, lono- and Osmoregulation. Proceedings in Life Sciences. Gilles R, Gilles-Baillien M, editors,. Springer, Berlin, Heidelberg, 1985. P. 341- 
20. Jeffs SA, Hurd H, Allen JT, Arme, C. Kinetics of molecular transfer across the tegument of protoscolices and hydatid cysts of Echinococcus granulosus and the relevance of these studies to drug targeting. In: Helminth Zoonoses. Geerts S, Kumar V, Brandt J, editors, Springer, Dordrecht, 1987. P. 37- 43.

21. Kwolek-Mirek M, Zadrag-Tecza R. Comparison of methods used for assessing the viability and vitality of yeast cells. FEMS Yeast Res. 2014; 14 (7):1068-1079.

22. Minois N, Frajnt M, Wilson C, Vaupel JW. Advances in measuring lifespan in the yeast Saccharomyces cerevisiae. P Natl Acad Sci. 2005; 102: 402- 406.

23. Lumsden RD. The tapeworm tegument: A model system for studies on membrane structure and function in host-parasite relationships. Trans Am Microsc Soc. 1975; 94(4):501-507.

24. Soulsby EJL. Helminths, Arthropods and Protozoa of Domesticated Animals. 7th edn. Bailliere Tindal, London,1982..

25. Abdel-Moemin A R. Effect of roselle calyces concentrate with other ingredients on the physiochemical and sensory properties of cupcakes. J Food Process Technol. 2016. 7, 603. Doi:10.4172/21577110.1000603.

26. Aishah B, Nursabrina M, Noriham A, Norizzah A R, Shahrimi HM. Anthocyanins from Hibiscus sabdariffa, Melastoma malabathricum and Ipomoea batatas and its color properties. Int Food Res. J. 2013; 20 (2): 827- 834.

\section{Figures}




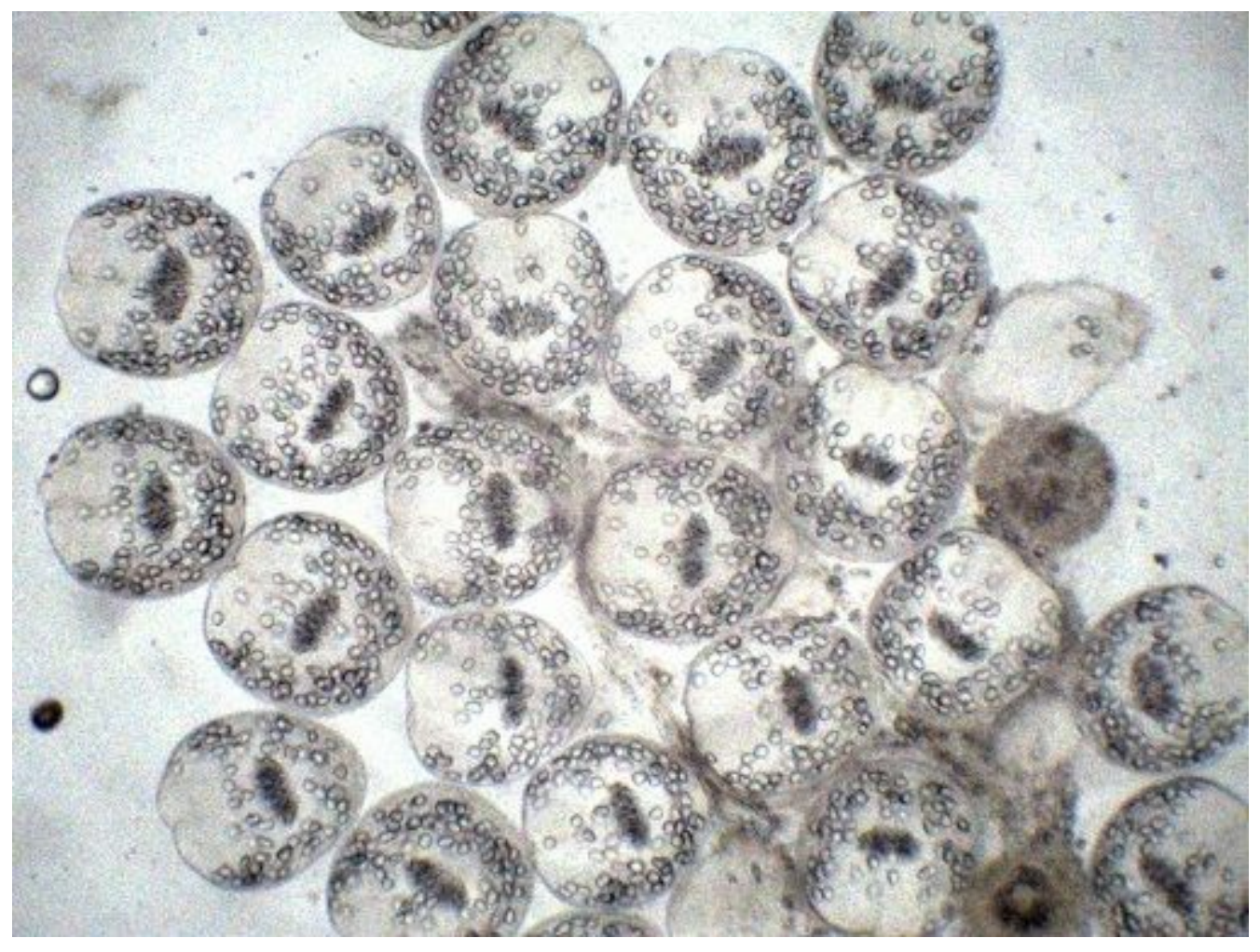

Figure 1

Fig. 1 Normal invaginated Echinococcus protoscolices showing the characteristic rostellar hooklets and calcareous corpuscles $(100 x)$

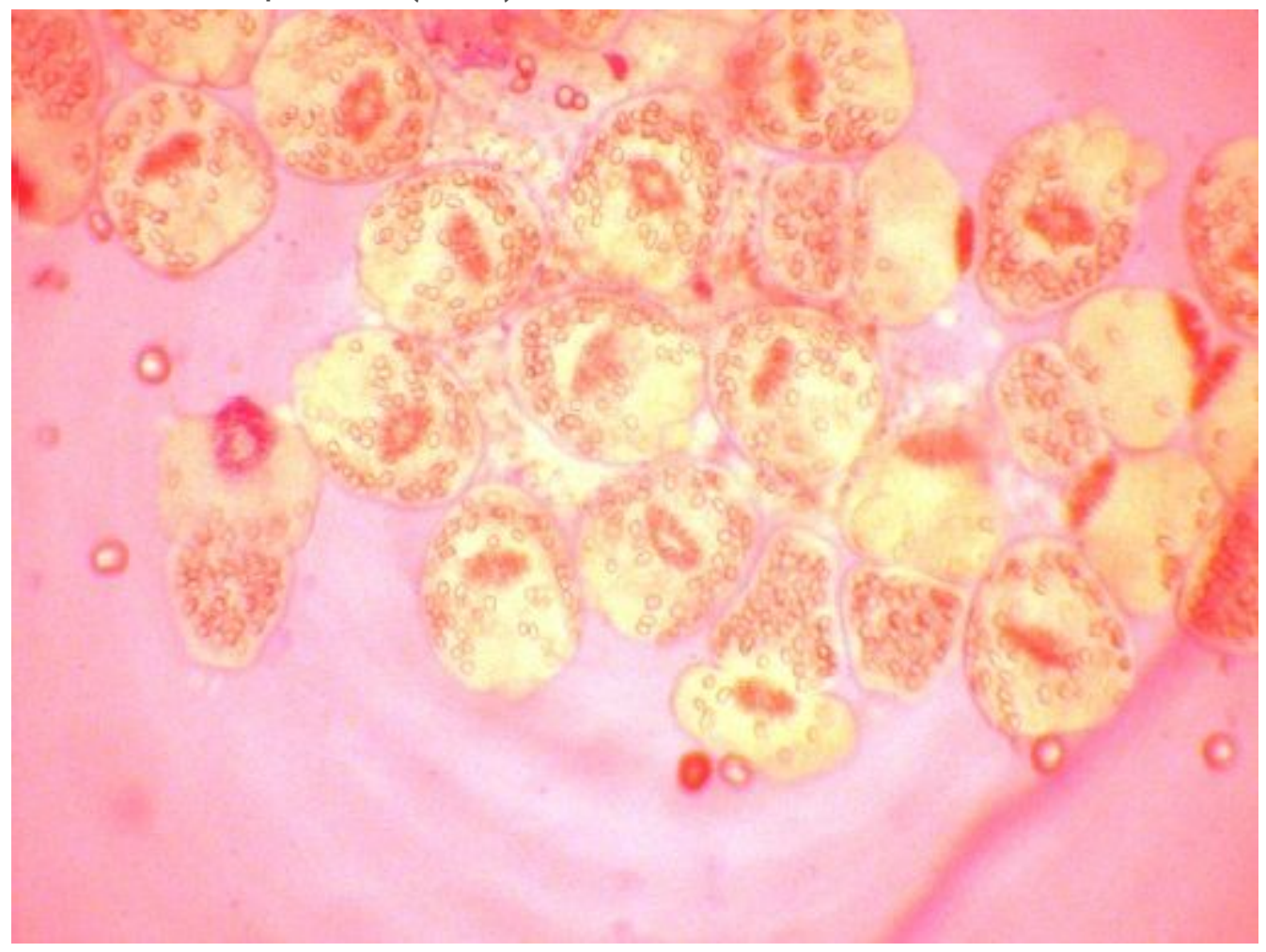

Figure 2

Fig. 2 Normal Echinococcus protoscolices exposed to eosin stain (Magnification 100x) 


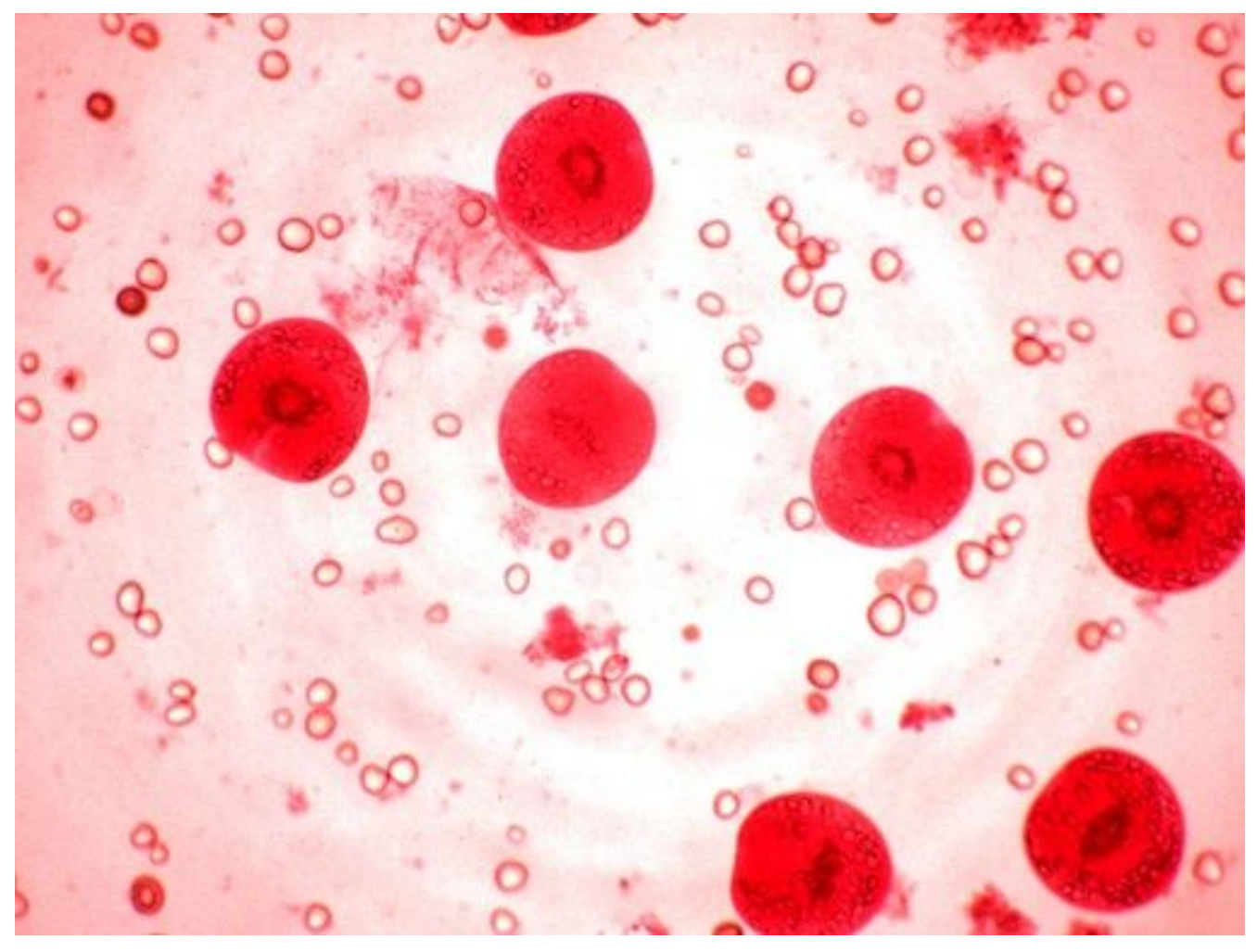

Figure 3

Fig. 3 Dead Echinococcus protoscolices exposed to eosin stain (100x)

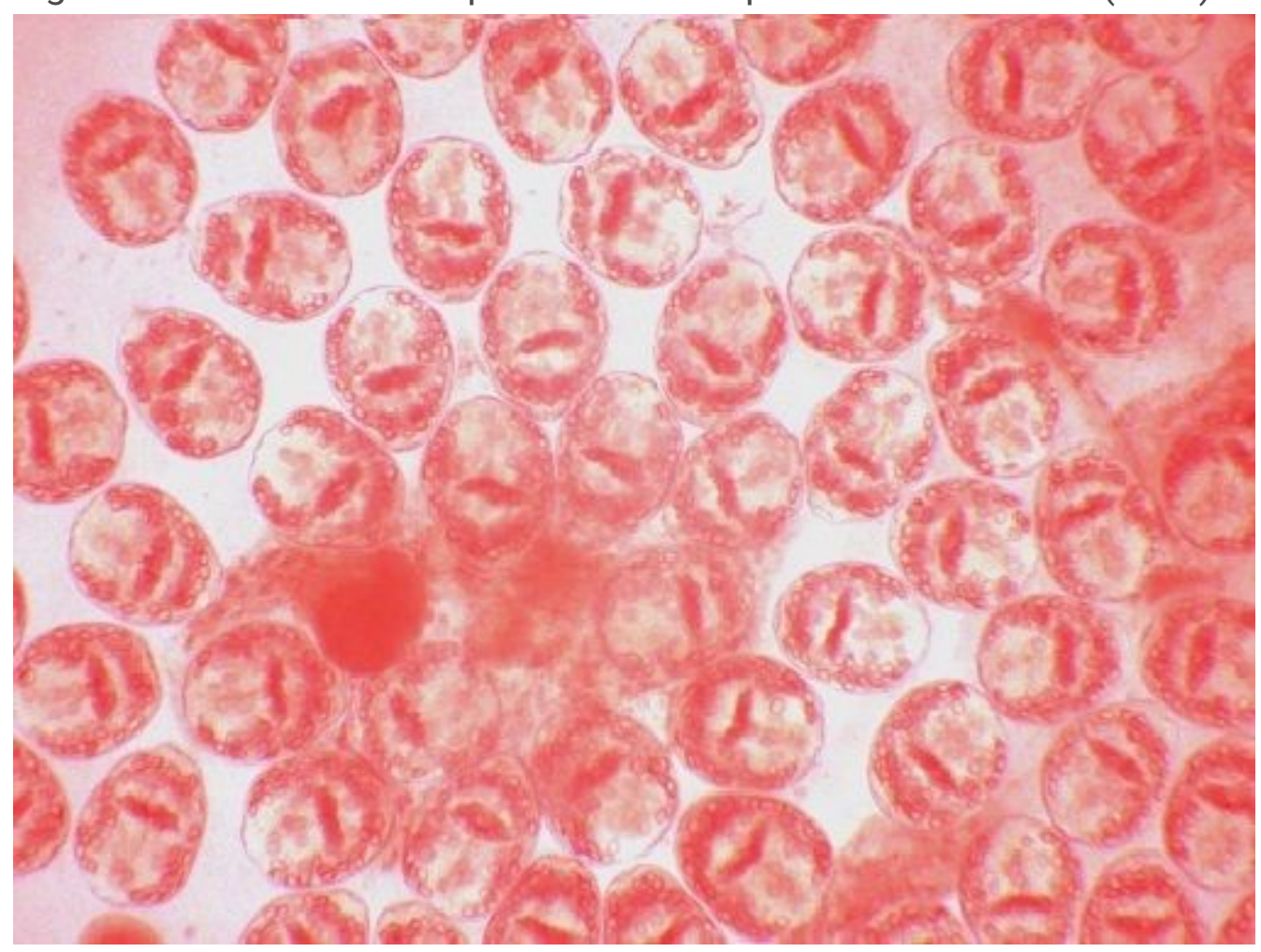

Figure 4

Fig. 4 Normal Echinococcus protoscolices exposed to H. sabdariffa calyx aqueous extract (100x) 


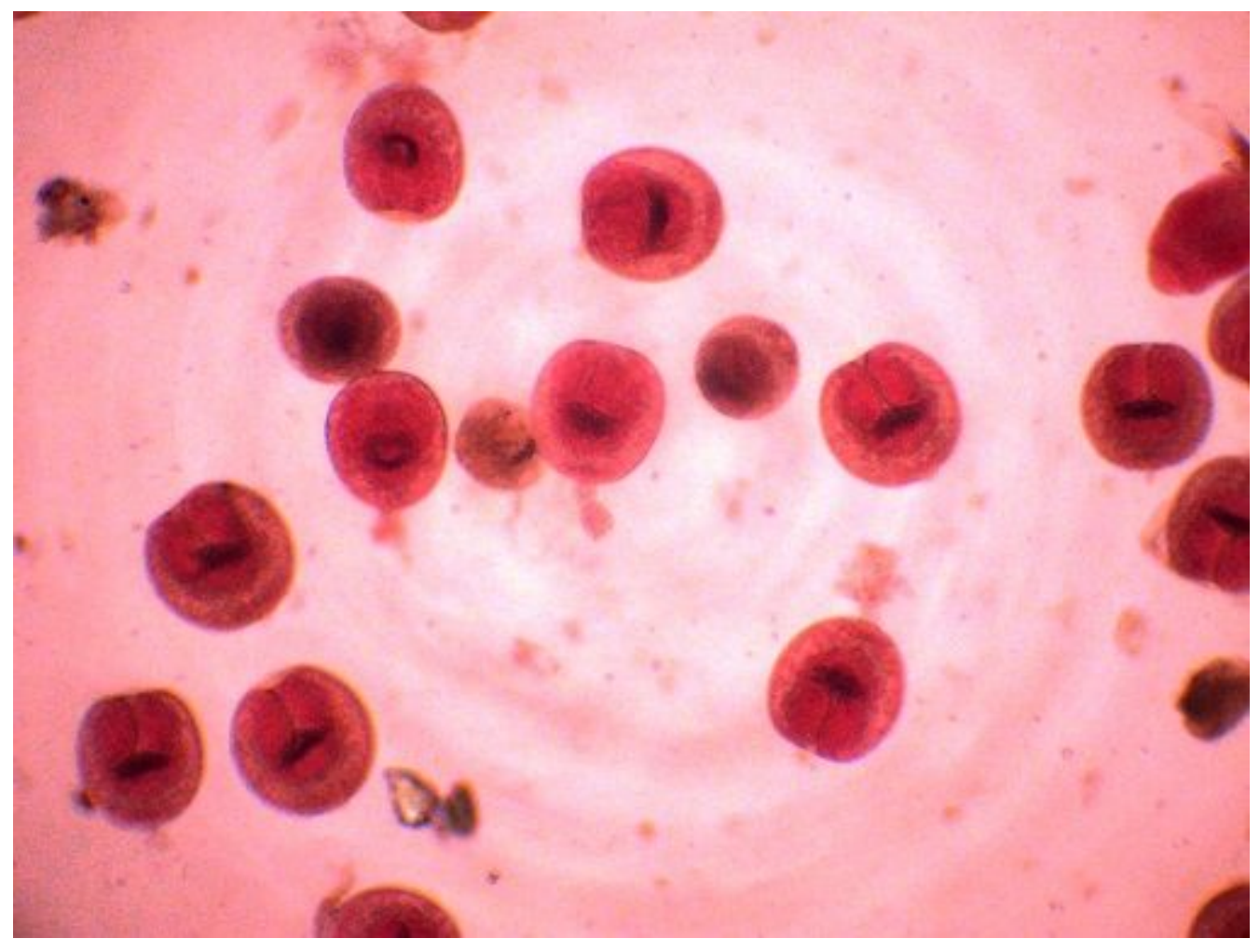

Figure 5

Fig. 5 Dead Echinococcus protoscolices exposed to H. sabdariffa calyx aqueous extract (100x)

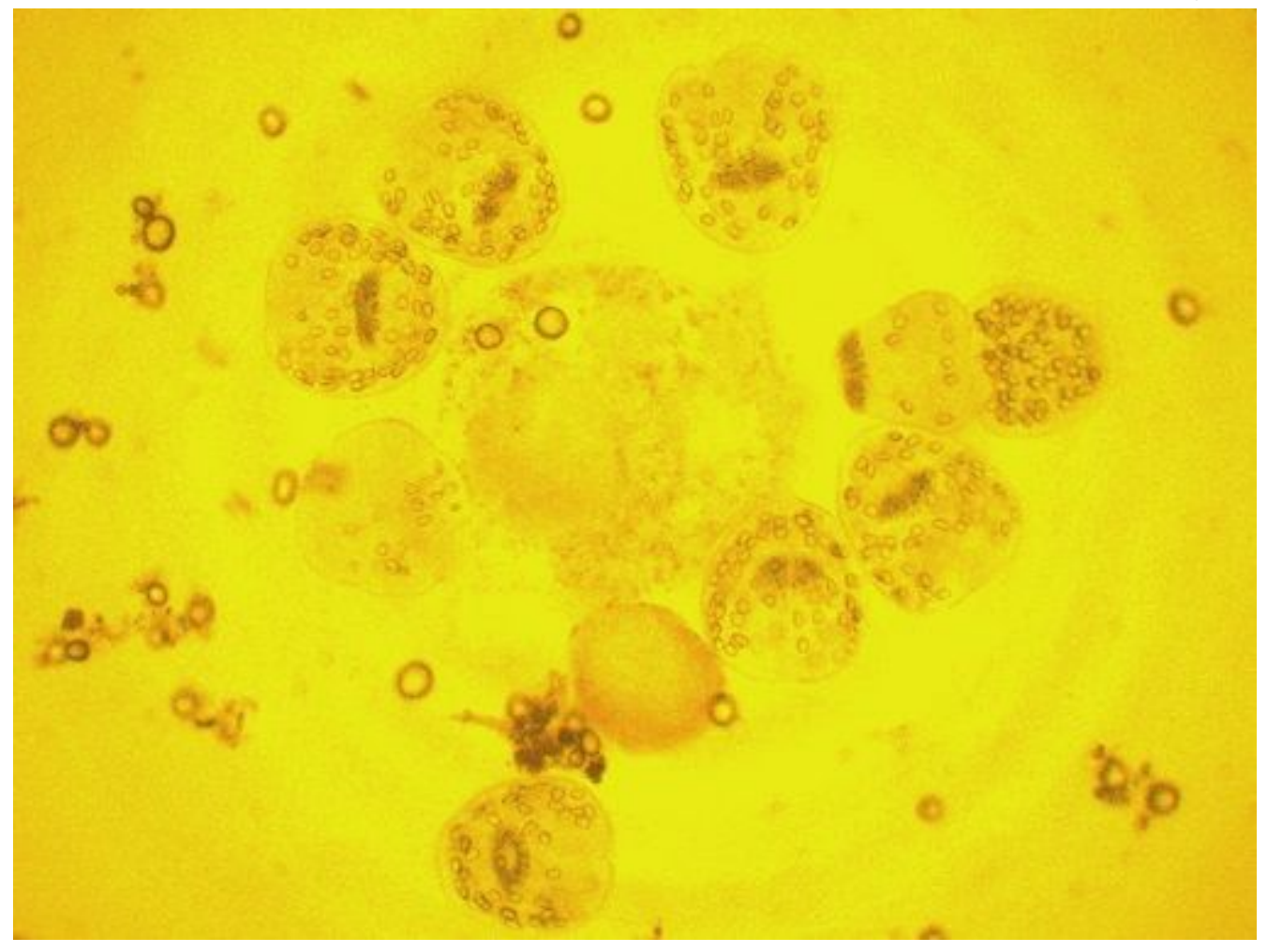

Figure 6

Fig. 6 Normal Echinococcus protoscolices exposed to L. inermis leaf aqueous extract (100x) 


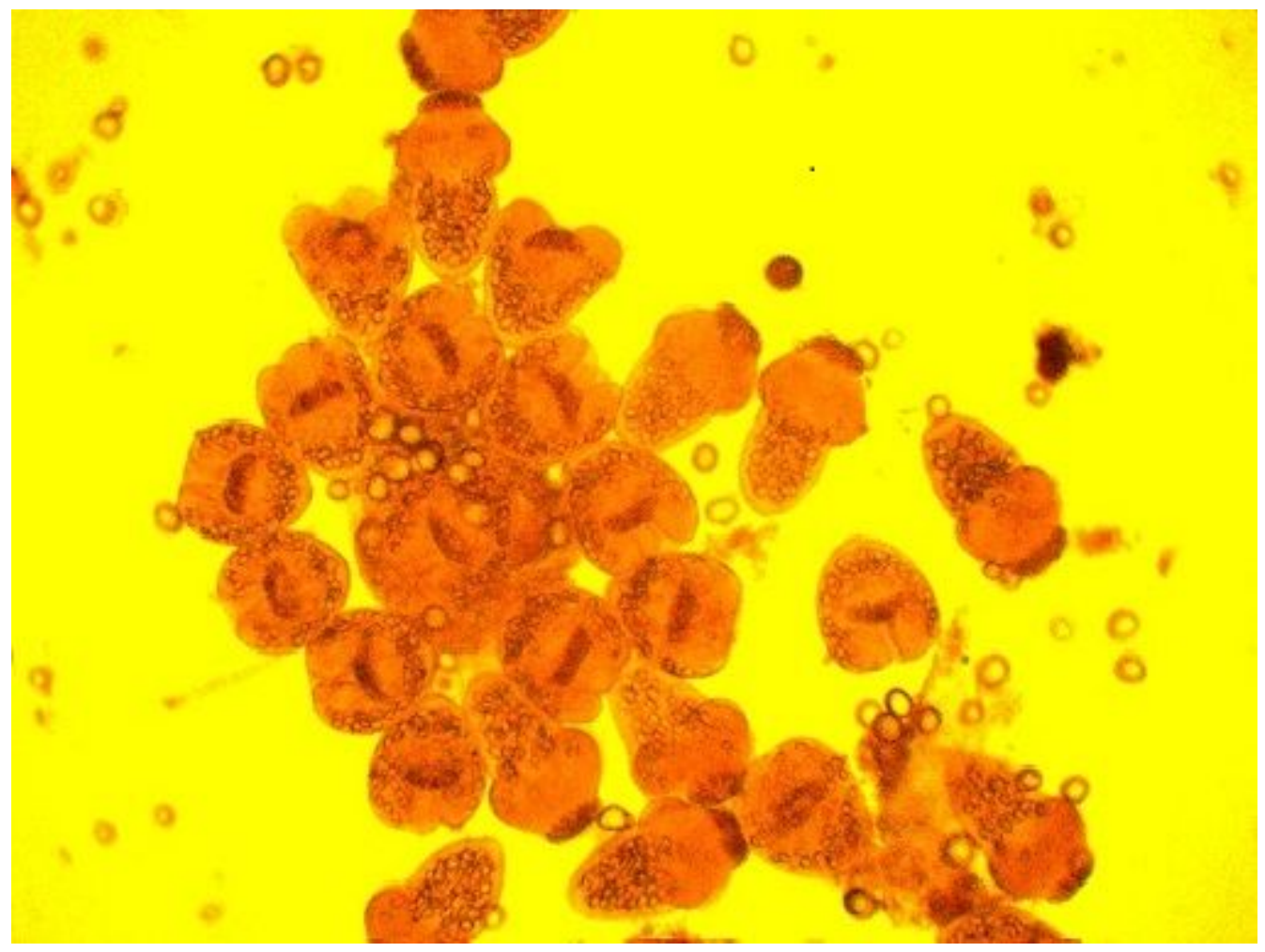

Figure 7

Fig. 7 Dead Echinococcus protoscolices exposed to L. inermis leaf aqueous extract (100x) 